chapter on the renal excretion of alkaline earths brings together some useful published data, the discussion of which is rather brief, but which is supported by a bibliography extending to thirty pages. Wasserman's and Taylor's contribution on calcium absorption, on the other hand, is less complete as a review of the subject, but provides an admirable account of their work on the calcium-binding protein.

The concluding chapters are by Manery on calcium and membrane and by Copp on calcium homeostasis. Manery's chapter overlaps to some extent with Winegrad's but may be read as complementary to it. Copp's contribution is inevitably a restatement of his previous views with only minor additions from recent work, but, as would be expected, it is readable and well informed.

The work as a whole is impressive, powerful and somewhat controversial, but it is stimulating and on the whole highly readable.

B. E. C. NorDIN

\section{HOST-PARASITE RELATIONS}

\section{Immunity to Parasitic Animals}

Edited by G. J. Jackson, Robert Herman and Ira Singer. Vol. 1. Pp. ix +292 . (North-Holland: Amsterdam; Appleton-Century-Crofts (Educational): New York, 1969.) $128 s$.

THE first book on the immunology of parasitic infections was that written by Taliaferro more than forty years ago. Since that time there have been notable advances in our knowledge of host-parasite relations, but in spite of all the new information the overall pattern remains obscure and is full of apparent anomalies and unanswered questions. In particular, attempts to control parasitic disease by immunological means have largely provod unrewarding. There are a few vaccines against protozoa and helminths which find application in veterinary practice, but none has proved sufficiently safe and potent to be used in human medicine. There are many reasons for this comparative failure. Not the least is the fascinating intricacy of the life cycles of many of these organisms, providing, at the same time, delight and frustration for those working in this ficld.

The editors of this review have planned a two volumo work, attempting a wide coverage of the subject. Tho first volume is largely devoted to the immunity (resistance?) shown by plants and by invertebrate and coldblooded vertebrate hosts to infection with animal parasites. The various contributors make it plain that these are neglected fields of research. Thus--"Our knowledge of the immune reactions of poikilothermic vertebrates to parasitic protozoa is little more than scant", and "No published reports were found on immunity of amphibians and reptiles to metazoan parasites". What reports there are in these fields tend to be widely dispersed (a paper on agglutinating antibodies in the trout appeared in a journal entitled The Progressive Fish Culturist!), and tho contributors are to be congratulated on achieving some synthesis of the literature. Their reviews will help to fill awkward gaps in the teaching on host-parasite relations and, it is hoped, will encourage more workers to explore theso ficlds.

Standing apart from the general body of the volume is the review by J. F. A. Sprent on evolutionary aspects of immunity in zooparasitic infections. Sprent attempts to define for the immunologist the special nature of the parasitic association and, for the parasitologist, what is meant by immunity. I doubt whether he succeeds, but the result is a discussion which will greatly interest those already familiar with the two disciplines.

Most workers in the field of parasite immunity are concerned with immunity shown by mammalian and avian hosts. While welcoming this first volume, they will look forward with more interest to the publication of the second.

R. J. T'ERRY

\section{BLOOD PARASITES OF SLOTHS}

The Haemoflagellates of Sloths

By J. J. Shaw. (London School of Hygiene and Tropical Medicine, Memoir No. 13.) Pp. xii $+132+13$ plates. (H. K. Lewis: London, 1969.) $70 s$.

THE sloth is a curious, exotic animal, whose name indicates its habits. It has an equally strange parasite-Endotrypanum schaudinni-a trypanosome which inhabits the red blood corpuscles of the animal. This unusual monograph gives an account of the sloth and the parasite. Actually, two genera of sloths are concerned-the twotoed genus Choloepus with two species, C. hoffmanni and $C$. didactylus, and the three-toed Bradypus with two species, B. griseus and $B$. infuscatus. Moreover, the researches of the author have demonstrated that two species of Endotrypanum (E. schaudinni and $E$. monteroge $i$ ) and two species of trypanosomes ( $T$. preguici and T. leeuwenhoeki) exist in the blood of these animals. The complex is analysed in relation to the biogeographical background: the habits of the sloths, the type of forest where infection takes place, and the biting arthropods which transmit the haemoflagellates.

The result of this approach is the elucidation, at least in part, of an interesting tropical problem. The author's own work was earried out in the forests of Costa Rica, Panama and Colombia; in addition, past records from Central America, Venezuela, French Guiana and northern Brazil are considered. Endotrypanum schaudinni was found in a third of more than a hundred specimens of the two-toed sloth; a new species, E. monterogei, was described from two specimens of the sloth; two new trypanosomes were also described from the animal. The Noguchi-Adler test was applied to determine the relationships of these organisms to each other and to a local human strain of Leishmania and of T. cruzi. They all seem to be immunologically distinct, though Endotrypanum is nearer to Leishmania than to the three trypanosomes. This affinity is confirmed by the results of cultivation at different temperatures in vitro, and by the apparent role of sandflies (Lutzomyia spp.) in transmission. The fine structure of E. schaudinni is described and the truly intra-erythrocytic position of the organism was confirmed; a peculiar pigment, allied perhaps to malarial haemazoin, was found in the parasites.

The hacmoflagellates of sloths have puzzled observers since the discovery of the first in 1908. This monograph is a major contribution to the subject, and although of a specialist nature should prove of interest to the landscape epidemiologist and general biologist.

The book is profusely illustrated by a colourod frontispieco and thirteen line drawings of the organisms, by various photographs of the sloths and their habitats, and by photomicrographs.

P. C. C. Garnham

\section{READ, LEARN AND INDIGEST}

\section{A Textbook of Practical Biology}

By George Usher. Pp. 208. (Constable: London, January 1970.) $45 s$.

THIs textbook is a programme of directions for basic practical work designed for A-level candidates particularly where overcrowded classes make it impossible for the student to have adequate individual attention. The author modestly proffers it as a compendium of work he has successfully carried out, the fruits of 12 yoars' experience in teaching A-level biological sciences.

The arrangement is systematic and covers the essentials of most A-level syllabuses in biology, botany and zoology, together with a great deal of simpler work usually regarded as pre-O-level. Although it is claimed that the student should be able to carry out the work on his own, some of it, notably that on Drosophila and on the examination of 